\title{
Ultrasound assisted green synthesis of cerium oxide nanoparticles using Prosopis juliflora leaf extract and their structural, optical and antibacterial properties
}

\author{
ThirunavukKarasu Arunachalam ${ }^{1, *}$, MuthukUmaran Karpagasundaram ${ }^{2}$, \\ NITHYA RAJARATHINAM ${ }^{1}$ \\ ${ }^{1}$ Department of Industrial Biotechnology, Government College of Technology, Coimbatore, 641013, India \\ ${ }^{2}$ Department of Chemistry, Government College of Technology, Coimbatore, 641013, India
}

\begin{abstract}
Cerium oxide nanoparticles (CONPs) were prepared using ultrasound assisted leaf extract of Prosopis juliflora acting as a reducing as well as stabilizing agent. The synthesized CONPs were characterized by ultraviolet-visible absorption spectroscopy (UV-Vis), particle size analyzer (PSA), Fourier transform infrared spectroscopy (FT-IR), Raman spectroscopy, X-ray diffraction (XRD), X-ray photoelectron spectroscopy (XPS) and high-resolution transmission electron microscopy (HRTEM). From the UV-Vis analysis, the optical band gap of the prepared CONPs $\left(\mathrm{E}_{\mathrm{g}}=3.62 \mathrm{eV}\right)$ was slightly increased as compared to the bulk ceria $\left(\mathrm{E}_{\mathrm{g}}=3.19 \mathrm{eV}\right)$. The phytochemicals in the extract reduced the particle size to $3.7 \mathrm{~nm} \pm 0.3 \mathrm{~nm}$, as it is evident from the PSA. FT-IR results confirmed the Ce-O stretching bands by showing the peaks at $452 \mathrm{~cm}^{-1}$. The Raman spectrum showed a characteristic peak shift for CONPs at $461.2 \mathrm{~cm}^{-1}$. XRD analysis revealed the cubic fluorite structure of the synthesized nanoparticles with the lattice constant, a of $5.415 \AA$ and unit cell volume, V of $158.813 \AA^{3}$. XPS signals were used to determine the concentration of $\mathrm{Ce}^{3+}$ and $\mathrm{Ce}^{4+}$ in the prepared CONPs and it was found that major amount of cerium exist in the $\mathrm{Ce}^{4+}$ state. HRTEM images showed spherical shaped particles with an average size of $15 \mathrm{~nm}$. Furthermore, the antibacterial activity of the prepared CONPs was evaluated and their efficacies were compared with the conventional antibiotics using disc diffusion assay against a set of Gram positive $(\mathrm{G}+$ ) bacteria (Staphylococcus aureus, Streptococcus pneumonia) and Gram negative $(\mathrm{G}-$ ) bacteria (Pseudomonas aeruginosa, Proteus vulgaris). The results suggested that CONPs showed antibacterial activity with significant variations due to the differences in the membrane structure and cell wall composition among the two groups tested.
\end{abstract}

Keywords: cerium oxide nanoparticles; Prosopis juliflora; structural, optical and antibacterial properties

\section{Introduction}

As the toxicological attributes of the conventional route of synthesizing metal and metal oxide nanoparticles are inevitable, an exponential increase in the search of an alternate route of synthesis exists in the recent scientific research. Plantderived products, such as the extracts of leaf, seed, and flower, play a vital role in chelating chemical compounds pointing out an effective, cleaner and eco-safe way of synthesizing nanoparticles. Green chemistry allows surface modification which has a strong influence on the physical, chemical, electrical, and optical properties of nanoparticles.

*E-mail: thiru@gct.ac.in
Cerium oxide $\left(\mathrm{CeO}_{2}\right)$, an oxide form of the rare earth metal cerium, is a known semiconductor with a wide band gap energy of $3.0 \mathrm{eV}$ to $3.9 \mathrm{eV}$ and large excitation energy [1]. $\mathrm{CeO}_{2}$ finds its applications in the fields of catalysis, sensors, fuel cells, cosmetics, biomedical and pathogenesis [2-6]. The biosynthetic route of $\mathrm{CeO}_{2}$ nanoparticles (CONPs) offers a wide range of advantages including ease of scale-up; it is bio-compatible and less timeconsuming than the conventional procedures which are complex and hazardous [7-16]. A recent synthesis of CONPs was made from food (honey [4], egg white [11]), by myogenesis (fungal extracellular compounds [17]) and from the leaf extracts of gloriosa superba L [6], hibiscus sabdariffa [18] and olea europaea [19]. The active biochemicals 
act as chelating, stabilizing and reducing agents to synthesize monodisperse nanocrystals of metal and metal oxide nanoparticles.

Prosopis juliflora, known as mesquite from the Fabaceae family, is native to Central and South America and an invader species in India that competes with the native species [20-22]. Being one of the prominent plants in the folkloric system of Indian medicine, the leaves were used to treat oral ailments [23], respiratory disorders [24], and as an insecticide [25]. The active phytochemicals from the classes of flavonoids, piperidine alkaloids (julifloricine, juliprosinene and juliflorine) and ellagic acid glycosides were shown to exhibit antimicrobial activity against several gram-positive bacteria and fungi [26-30]. This study aims to utilize these bioactive chemicals as an effective reducing and stabilizing agents for the synthesis of CONPs. To accomplish this, the study used ultrasound mediated leaf extract of $P$. juliflora to synthesize and characterize them. Also, the cytotoxic behavior of the prepared CONPs was exploited against the set of Gram positive $(\mathrm{G}+)$ and Gram negative $(\mathrm{G}-)$ bacterial systems.

\section{Experimental}

\subsection{Preparation of ultrasound assisted leaf extract of Prosopis juliflora}

Prosopis juliflora leaves were dried, powdered and sieved to the size of $\mathrm{d}<100 \mu \mathrm{m}$. An aliquot of $0.5 \mathrm{~g}$ of leaf powder was accurately weighed and extracted with $100 \mathrm{~mL}$ of double distilled water in the ultrasonic cleaning bath (Citizon digital ultrasonic cleaner) at $40 \mathrm{kHz}$ and $120 \mathrm{~W}$ and sonicated for $10 \mathrm{~min}$. After sonication, the solution was cooled to the room temperature. The ultrasound assisted extract of yellowish green color was filtered using Whatman filter $0.45 \mu \mathrm{m}$ and stored at $5{ }^{\circ} \mathrm{C}$ for further use.

\subsection{Synthesis of cerium oxide nanoparti- cles using ultrasound assisted $\boldsymbol{P}$. juliflora leaf extract}

In a typical procedure, $0.1 \mathrm{M}$ cerium chloride (99.5\%, analytical grade) aqueous solution was prepared and mixed dropwise with an equal volume of $P$. juliflora leaf extract. The formation of white precipitate indicated that the hydroxide mediated precipitation occurred in the solution. The solution was heated at $80{ }^{\circ} \mathrm{C}$ in an oven till half of its volume. The precursor was then kept in the microwave oven, operated at a power of $800 \mathrm{~W}$ with the frequency $2450 \mathrm{MHz}$ for $10 \mathrm{~min}$. A yellowish brown precipitate started to appear which suggested the formation of cerium oxide nanoparticles. The obtained precipitate was powdered and annealed at $800{ }^{\circ} \mathrm{C}$ for $2 \mathrm{~h}$. A schematic diagram of the formation of $\mathrm{CeO}_{2}$ NPs using ultrasound assisted P. juliflora leaf extract is shown in Fig. 1.

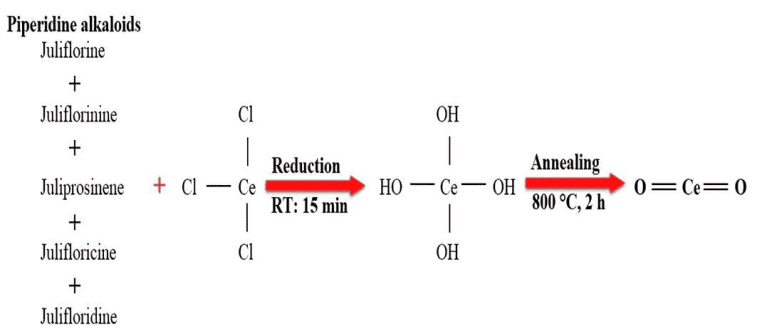

Fig. 1. Formation of CONPs using P. juliflora leaf extract.

\subsection{Characterization of $\mathrm{CeO}_{2} \mathrm{NPs}$}

UV-Vis spectrophotometer (Varian Cary 50) was used to record the optical absorption of the green synthesized nanoparticles in the spectral range of $200 \mathrm{~nm}$ to $850 \mathrm{~nm}$. The particle sizes were measured using PSA at $25^{\circ} \mathrm{C}$ at $90^{\circ} / 173^{\circ}$ scattering angle (Horiba Scientific Nanopartica SZ-100). Fourier transform infra-red spectroscopy (FT-IR) analysis was carried out in the range of $400 \mathrm{~cm}^{-1}$ to $4000 \mathrm{~cm}^{-1}$ (Perkin Elmer). Raman shifts were measured using Raman spectrophotometer (R-3000 QE TM) with the spectral range of $200 \mathrm{~cm}^{-1}$ to $2000 \mathrm{~cm}^{-1}$. XRD pattern was recorded on Powder XRD (Bruker D8 Advance Powder X-ray Diffractometer, Germany) using $\mathrm{CuK} \alpha$ radiation $(\lambda=1.54060 \AA)$ for measuring the crystalline nature of atoms in the material. The diffractograms were recorded in the range of $2 \theta$ from $20^{\circ}$ to $90^{\circ}$ at a scanning speed of $2 \% \mathrm{~min}$ at room temperature. The average crystallite size 
of the synthesized CONPs was calculated using Scherrer formula. XPS signals were detected at a pressure using ultra-high vacuum with $\mathrm{AlK} \alpha$ excitation at $400 \mathrm{~W}$ (Thermo Scientific). The morphology of the synthesized CONPs was examined using HRTEM. Samples for TEM analysis were prepared by drop coating the nanosols on carboncoated copper grids at ambient temperature. The excess nanoparticle solution was removed with a filter paper. The copper grid was finally dried at room temperature and was subjected to HRTEM analysis by the instrument JEOL JEM 2100 model operated at an accelerating voltage of $200 \mathrm{kV}$. All the graphs were prepared using origin 8.6 evaluation software.

\subsection{Determination of zone of inhibition (ZOI) and minimum inhibitory concentra- tion (MIC)}

The Gram positive (G+) (Staphylococcus aureus, Streptococcus pneumoniae) and Gram negative (G-) (Pseudomonas aeruginosa, Proteus vulgaris) bacterial cell suspensions were taken from $\log$ phase $\left(10^{6} / \mathrm{mL}\right)$ and cultured in Mueller Hinton Broth (MHB). The disc diffusion assay was performed for three different concentrations of CONPs $(10 \mathrm{mg} / \mathrm{L}, 50 \mathrm{mg} / \mathrm{L}$ and $100 \mathrm{mg} / \mathrm{mL})$ against the set of bacteria as described previously using Mueller Hinton agar [31]. Each test strain was inoculated in the plates containing $50 \mathrm{mg} / \mathrm{mL}$ of CONPs treated discs and a solution of chloramphenicol antibiotic $(5 \mathrm{mg} / \mathrm{mL})$ treated discs along with the deionized water as negative control. A zone of inhibition was observed for each strain tested after incubation for $24 \mathrm{~h}$ at $37{ }^{\circ} \mathrm{C}$ and the all antibacterial activity was performed in triplicates. To determine the MICs, about $0.1 \mathrm{~mL}$ of culture suspensions were dispensed into a 96-well microtiter plate and then exposed to CONPs $(50 \mathrm{mg} / \mathrm{mL})$ and a set of screened antibiotics with the defined concentrations (Table 1). The growth was observed by measuring the absorbance at $600 \mathrm{~nm}$. The observed MICs of nanoparticles were listed in Table 2.

\section{Results and discussion}

\subsection{UV-Vis spectroscopy studies}

Fig. 2 shows the UV-Vis absorption spectrum of ultrasound assisted green synthesized CONPs. The presence of piperidine alkaloids reduced the precursor into cerium hydroxide, upon oxidation resulting in smaller particles of cerium oxide. This effect can be observed by the shift in the absorption peak into UV-Vis region $[9,11,13,14]$. The optical band gap can be determined with the help of equation 1 [6]:

$$
\alpha h v=A\left(h v-E_{g}\right)^{0.5}
$$

where $\alpha$ is the absorption coefficient, hv is the photon energy and $E_{\mathrm{g}}$ is the direct band gap. The direct optical band gap of the prepared CONPs was found to be $3.62 \mathrm{eV}$ as it has been observed by Arumugam et al. [6], showing a slight increase in the band gap when compared with the bulk ceria. This increase in the band gap could be observed either through quantum size effect or through the charge transition of cerium ions $[32,33]$.

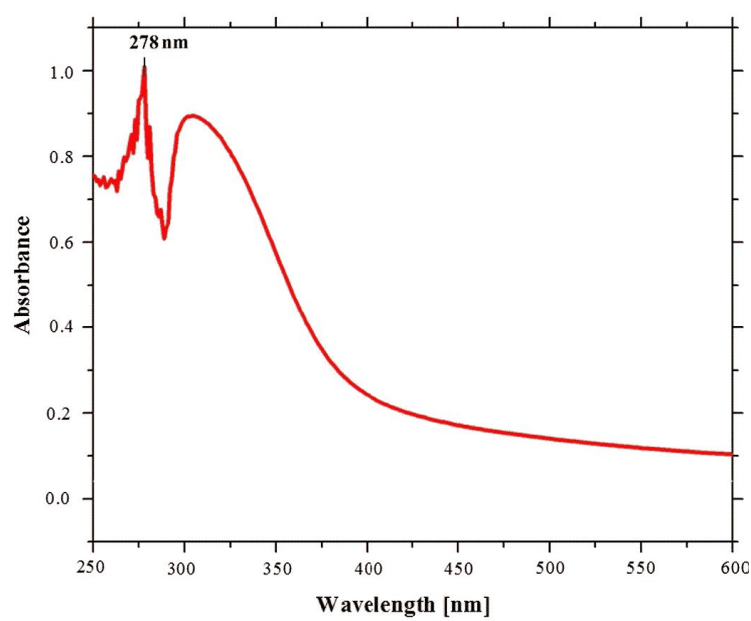

Fig. 2. UV-Vis spectrum of the green synthesized CONPs.

\subsection{Particle size analysis}

PSA was carried out using the dynamic light scattering technique at $173^{\circ}$ scattering angle at room temperature (Horiba Scientific Nanopartica 
Table 1. Concentration of the screened antibiotics based on CLSI standards.

$$
\text { Antibiotic concentration }\left[\mu \mathrm{g} \cdot \mathrm{mL}^{-1}\right]
$$

Ampicillin Chloramphenicol Erythromycin Gentamicin Tetracycline Kanamycin

\begin{tabular}{llllll}
\hline \hline 10 & 30 & 15 & 10 & 30 & 30 \\
\hline
\end{tabular}

Table 2. Determination of MIC value of antibiotics and CONPs.

\begin{tabular}{|c|c|c|c|c|c|c|c|}
\hline \multirow{2}{*}{ Species } & \multicolumn{7}{|c|}{$\mathrm{MIC}\left[\mu \mathrm{g} \cdot \mathrm{mL}^{-1}\right]$} \\
\hline & Ampicillin & Chloramphenicol & Erythromycin & Gentamicin & Tetracycline & Kanamycin & CONPs \\
\hline \multicolumn{8}{|l|}{$\mathrm{G}(+)$} \\
\hline Staphylococcus aureus & 4 & 8 & 4 & 4 & 3 & 3 & 4 \\
\hline Streptococcus pneumonia & 4 & 8 & 4 & 4 & 3 & 3 & 4 \\
\hline \multicolumn{8}{|l|}{$\mathrm{G}(-)$} \\
\hline Pseudomonas aeruginosa & 2 & 4 & 2 & 2 & 3 & 2 & 2 \\
\hline Proteus vulgaris & 2 & 4 & 2 & 2 & 3 & 2 & 2 \\
\hline
\end{tabular}

SZ-100). Initially, the sample was prepared by dispersing a small amount of CONPs in $0.2 \%$ sodium metahexaphosphate water and sonicated for $20 \mathrm{~min}$. The viscosity of the dispersion medium was found to be $1.084 \mathrm{mPa} \cdot \mathrm{s}$. The mean diameter of the particles was assessed as $3.7 \mathrm{~nm}$ with the standard deviation of $0.3 \mathrm{~nm}$ (Fig. 3).

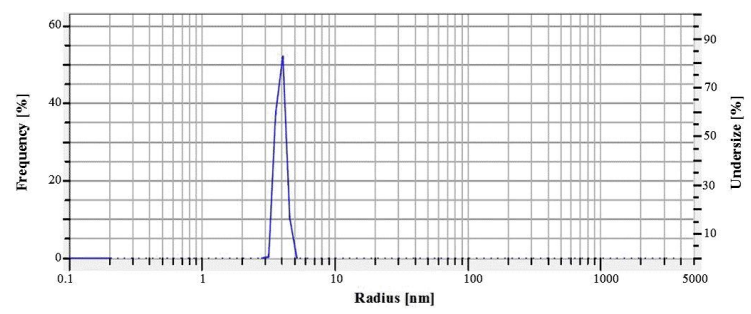

Fig. 3. PSA of the ultrasound assisted green synthesized CONPs.

\subsection{Fourier transform infrared spec- troscopy}

FT-IR spectra of the synthesized CONPs are shown in Fig. 4. The spectra were obtained using the $\mathrm{KBr}$ pellet method in the wave number range $400 \mathrm{~cm}^{-1}$ to $4000 \mathrm{~cm}^{-1}$. As it is evident from the spectra, the absorption range of $3800 \mathrm{~cm}^{-1}$ to $3000 \mathrm{~cm}^{-1}$ corresponds to the $\mathrm{O}-\mathrm{H}$ stretching frequency. The absorption peak at $3480.29 \mathrm{~cm}^{-1}$ confirms the presence of CONPs. As cerium oxide readily traps atmospheric $\mathrm{CO}_{2}$, their corresponding peaks were observed at $2426 \mathrm{~cm}^{-1}$ and $1385 \mathrm{~cm}^{-1}$. The Ce-O stretching frequency was expected below $400 \mathrm{~cm}^{-1}$ but in this study it was observed at $452 \mathrm{~cm}^{-1}$, indicating the formation of $\mathrm{CeO}_{2}$ [13]. Similar observations were reported by Goharshadi et al. [34] where the $\mathrm{Ce}-\mathrm{O}$ stretching band appeared in $450 \mathrm{~cm}^{-1}$.

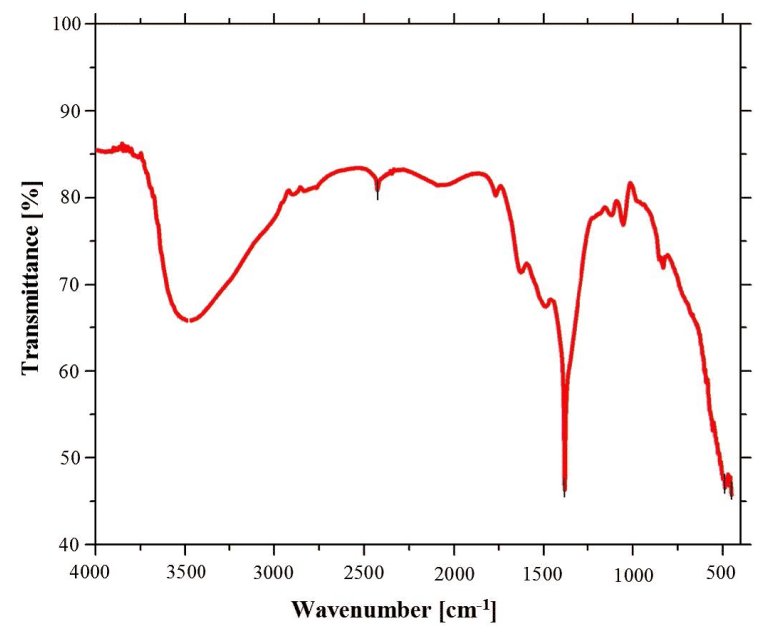

Fig. 4. FT-IR spectrum of the ultrasound assisted green synthesized CONPs.

\subsection{Raman spectroscopy}

Fig. 5 shows a Raman spectrum of the CONPs. The sharp peak is observed at $461.2 \mathrm{~cm}^{-1}$, 
which is very similar to the results reported in the literature [21, 22]. The appearance of such shift may be due to the symmetrical stretching mode of the $\mathrm{Ce}-\mathrm{O}$ vibrational unit that is highly sensitive to any disorder in the oxygen sublattice $[35,36]$. The particle size of the CONPs can be estimated using the following equation [37-39]:

$$
\Gamma=10+\frac{124.7}{D}
$$

where $\Gamma\left(\mathrm{cm}^{-1}\right)$ is the FWHM of the Raman active mode peak and D is the particle size. From the results, the calculated particle size was found as $11.47 \mathrm{~nm}$, which is comparable with the XRD analysis.

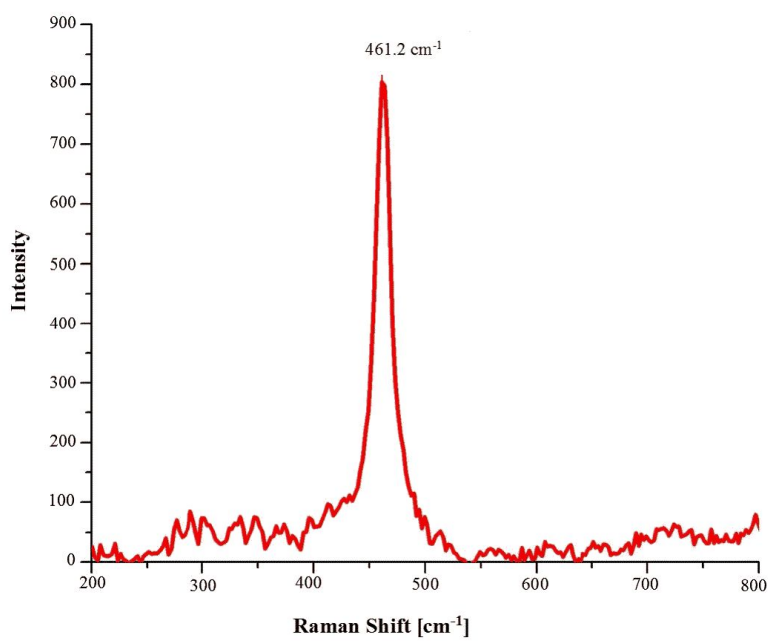

Fig. 5. Raman spectrum of the ultrasound assisted green synthesized CONPs.

\subsection{X-ray diffraction analysis}

XRD results showed that the synthesized nanoparticles exist in the face-center cubic phase of CONPs (JCPDS Card No. 34-0394) what can be confirmed from the peaks obtained at $2 \theta$ angles. Fig. 6 shows 9 peaks located at angles $(2 \theta)$ of $28.54^{\circ}, 33.08^{\circ}$ and $47.38^{\circ}$ corresponding to $\left(\begin{array}{lll}1 & 1 & 1\end{array}\right)$, (2 00 ) and (2 20 ) planes of the CONPs. Similarly, other peaks found at angles $(2 \theta)$ of $56.33^{\circ}, 59.08^{\circ}$, $69.39^{\circ}, 76.54^{\circ}, 78.99^{\circ}$ and $88.22^{\circ}$ correspond to (3 11 1), (2 22 2), (4 00 0), (3 3 1 $),\left(\begin{array}{lll}4 & 2 & 0\end{array}\right)$ and (4 22 2) planes. The lattice constant a of CONPs was found to be $5.415 \AA$ by using the following relation [6]:

$$
\frac{1}{d^{2}}=\frac{\left(h^{2}+k^{2}+l^{2}\right)}{a^{2}}
$$

The unit cell volume (V) was calculated as third power of the lattice constant and found as $158.813 \AA^{3}$. Debye-Scherrer formula (equation 4) was used to determine the average crystallite size of the particles:

$$
D=\frac{0.9 \lambda}{\beta \cos \theta}
$$

where $D$ is the average crystallite size, $\lambda$ is the wavelength of X-ray used (1.54060 $\AA$ ), $\beta$ is the angular peak width at half maximum (rad) and $\theta$ is Bragg's diffraction angle. The average crystallite size was estimated as $11.42 \mathrm{~nm}$ for CONPs.

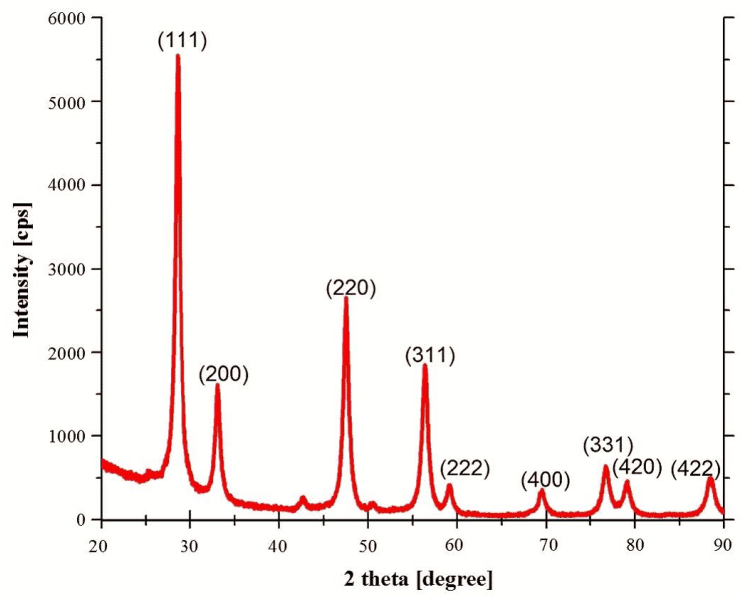

Fig. 6. XRD pattern of the ultrasound assisted green synthesized CONPs.

\subsection{X-ray photoelectron spectroscopy}

The percentage composition of different oxidation states of each element in the sample can be computed with the help of XPS signals. Fig. 7 shows the $\mathrm{Ce}_{3 \mathrm{~d}}$ scan for the synthesized CONPs. The XPS spectrum can be split into Ce $3 \mathrm{~d}_{5 / 2}$ and Ce $3 d_{3 / 2}$ with multiple up-down satellites, which correspond to the $\mathrm{v}$ and $\mathrm{u}$ spin orbit coupling, respectively. The peaks obtained between 875 and 
$900 \mathrm{eV}$ belong to the Ce $3 \mathrm{~d}_{5 / 2}$ and above $900 \mathrm{eV}$ they refer to $\mathrm{Ce} 3 \mathrm{~d}_{3 / 2}$ [40]. The peak observed at $923 \mathrm{eV}$ is a characteristic satellite peak indicating the presence of $\mathrm{Ce}^{4+}$. From Fig. 7, the observed peaks at $889.02 \mathrm{eV}, 892.40 \mathrm{eV}, 895.66 \mathrm{eV}$, $898.08 \mathrm{eV}$ correspond to the Ce $3 \mathrm{~d}_{5 / 2}$. Similarly, the peaks at $904.87 \mathrm{eV}, 907.84 \mathrm{eV}, 913.54 \mathrm{eV}$, $923.28 \mathrm{eV}$ belong to the $\mathrm{Ce} 3 \mathrm{~d}_{3 / 2}$. Table 3 shows the peak assignments for the multiplets $\mathrm{u}$ and $\mathrm{v}$. The peaks were fitted in the Gaussian-Lorentzian model using Origin 8.6 and their relative concentration estimation (equation 5 and equation 6) showed that the cerium in the synthesized CONPs exists in the $\mathrm{Ce}^{4+}$ state rather than in the $\mathrm{Ce}^{3+}$ state:

$$
\begin{gathered}
C e^{3+}=v_{0}+v^{\prime}+u_{0}+u^{\prime} \\
C e^{4+}=v+v^{\prime \prime}+u+u^{\prime \prime} \\
{\left[C e^{3+}\right]=\frac{C e^{3+}}{C e^{3+}+C e^{4+}}}
\end{gathered}
$$

Table 3. Ce 3d peak assignments.

\begin{tabular}{cccccc}
\hline & & $\mathrm{v}_{0}$ & $\mathrm{v}$ & $\mathrm{v}^{\prime}$ & $\mathrm{v}^{\prime \prime}$ \\
\hline \hline \multirow{2}{*}{$\mathrm{Ce} 3 \mathrm{~d}_{5 / 2}$} & Origin & $\mathrm{Ce}^{3+}$ & $\mathrm{Ce}^{4+}$ & $\mathrm{Ce}^{3+}$ & $\mathrm{Ce}^{4+}$ \\
\cline { 2 - 6 } & FWHM & 4.74 & 10.11 & 6.23 & 11.15 \\
\hline & $\mathrm{u}_{0}$ & $\mathrm{u}$ & $\mathrm{u}^{\prime}$ & $\mathrm{u}^{\prime \prime}$ \\
\hline \multirow{2}{*}{$\mathrm{Ce} 3 \mathrm{~d}_{3 / 2}$} & Origin & $\mathrm{Ce}^{3+}$ & $\mathrm{Ce}^{4+}$ & $\mathrm{Ce}^{3+}$ & $\mathrm{Ce}^{4+}$ \\
\cline { 2 - 6 } & FWHM & 5.78 & 8.44 & 17.06 & 19.93 \\
\hline
\end{tabular}

\subsection{Transmission electron microscopy}

Fig. 8a to Fig. 8c show HRTEM images of the CONPs and the mean particle size is about $15 \mathrm{~nm}$ for the spherical structure. Fig. 8d shows clear Debye-Scherrer diffraction rings in the SAED pattern implying the high crystallinity of the CONPs. The rings can be appropriately assigned to the Miller indices (1 111 1 $),\left(\begin{array}{lll}2 & 0 & 0\end{array}\right),\left(\begin{array}{lll}2 & 2 & 0\end{array}\right),\left(\begin{array}{lll}3 & 1 & 1\end{array}\right)$, (2 2 2), (4 $\left.\begin{array}{lll}0 & 0\end{array}\right),\left(\begin{array}{lll}3 & 3 & 1\end{array}\right),\left(\begin{array}{lll}4 & 2 & 0\end{array}\right),\left(\begin{array}{lll}4 & 2 & 2\end{array}\right)$ and $\left(\begin{array}{lll}5 & 1 & 1\end{array}\right)$ of cubic fluorite CONPs.

\subsection{Antibacterial analysis of CONPs}

Fig. 9 shows the size measurements of ZOI around CONPs and antibiotic treated discs. In

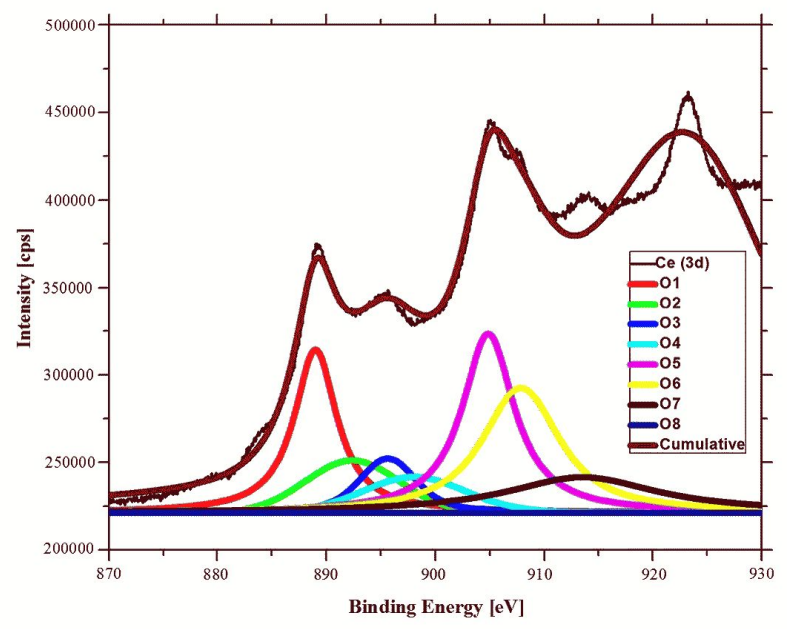

Fig. 7. XPS peak fit of the ultrasound assisted green synthesized CONPs.

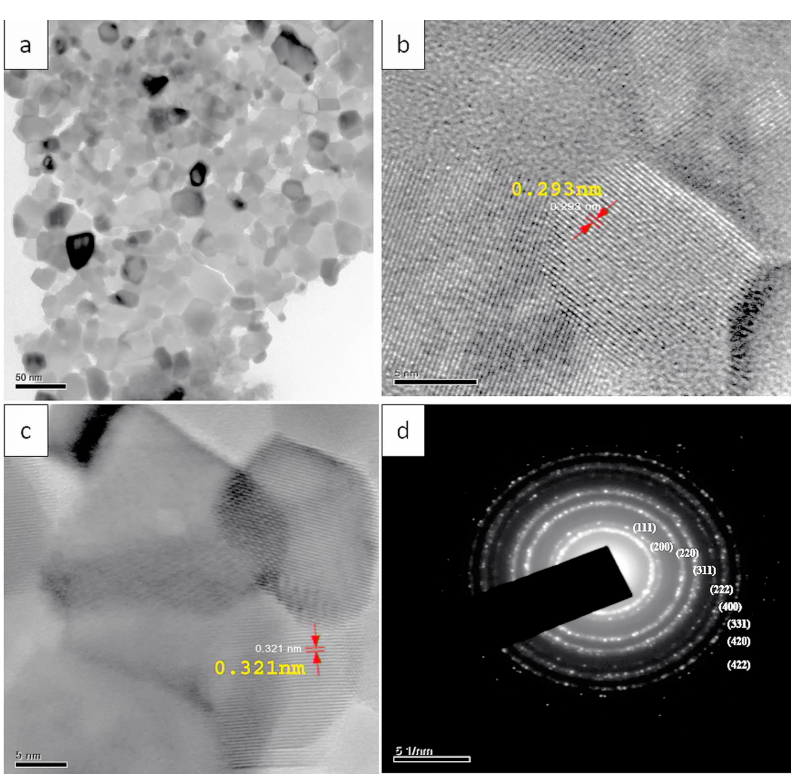

Fig. 8. HRTEM images of the ultrasound assisted green synthesized CONPs.

the case of $P$. aeruginosa, $P$. vulgaris, ZOIs of $4.09 \pm 0.22 \mathrm{~mm}$ and $4.38 \pm 0.44 \mathrm{~mm}$ were observed, respectively, which shows mild to moderate antibacterial behavior. On contrary, ZOIs of $12.43 \pm 0.36 \mathrm{~mm}$ and $14.56 \pm 0.23 \mathrm{~mm}$ were recorded against $S$. aureus and $S$. pneumonia, respectively, for $100 \mathrm{mg} / \mathrm{mL}$ of CONPs. This significant difference in ZOI might be due to the differences in the membrane structure and cell wall 


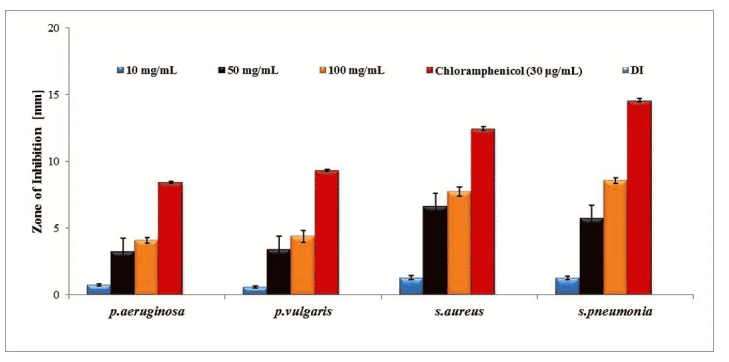

Fig. 9. Antibacterial activity of the ultrasound assisted green synthesized CONPs.

composition among them. Similar results were reported by Arumugam et al. [6]. On comparing to the chemical synthesis of CONPs, which is highly cytotoxic to somatic cells [41], the green synthesized particles show low genotoxic and cytotoxic behavior towards healthy cells [42]. From the results of XRD, Raman and TEM, the average CONPs size was found to be $15 \mathrm{~nm}$, with the smaller crystallite size being $3 \mathrm{~nm}$. The smaller crystallite size results in greater antibacterial activity due to their increased surface area [43]. Among the dependent variables including size, surface area and morphology, the cytotoxic efficiency depends mainly on the polar surface of the particles [4446]. The surface interaction may cause the reactive oxygen species (ROS) to increase its level, resulting in the cell under oxidative stress [47]. The most significant ROS include reactive hydroxyl radical $(\cdot \mathrm{OH})$, less toxic superoxide anion radical $\left(-\cdot \mathrm{O}_{2}\right)$, and singlet oxygen $\left({ }_{1} \mathrm{O}^{2}\right)$ with a weaker oxidizer, creating oxidative stress which results in significant damage in cell structures [48]. The mechanism of cell death could be possibly explained by the denaturation of the membrane surface proteins through the interaction of their surface thiol $(-\mathrm{SH})$ group with the released ions of the nanoparticles [49]. The variation of band gap energy for the CONPs on comparing with the bulk ceria may also assist in the increased ROS production as it is evident from the UV-Vis analysis.

\section{Conclusions}

The ultrasound assisted leaf extract of $P$. juliflora proved to be an effective reducing and stabilizing agent for the green synthesis of highly crystalline and extremely small sized CONPs. The UV-Vis, PSA and FT-IR studies revealed the formation of CONPs. XRD, Raman and SAED analysis validated the presence of highly monodisperse nanoparticles of cerium oxide. XPS signals were fitted using a Gaussian/Lorentzian model and confirmed that the cerium exists in the $\mathrm{Ce}^{4+}$ state more prevalent than $\mathrm{Ce}^{3+}$. HRTEM images confirmed that the CONPs possessed octahedral morphology with the average size of $15 \mathrm{~nm}$. Smaller sized particles, rigid morphology, surface interaction and variation in the band gap energy of the synthesized CONPs induced the generation of ROS species, which showed an effective cytotoxic activity. The toxicological behavior of the CONPs is mild and moderate in G- strain and highly potent in $\mathrm{G}+$ strains due to their membrane complexity. From the results of the present study we can infer that the CONPs synthesized through green chemistry possess good potential in the application of antimicrobial therapies.

\section{References}

[1] Miao J.J., WAng H., Li Y.R., ZhU J.M., ZHU J.J., J. Cryst. Growth, 281 (2005), 525.

[2] Korsvik C., Patil S., Seal S., Self S., Chem. Commun., 10 (2007), 1056.

[3] Chandar K.N., Jayavel R., Physica E, 58 (2014), 48.

[4] Darroudi M., Hoseini S.J., Oskuee R.K., HosSeini H.A., Gholami L., Gerayli S., Ceram. Int., 40 (2013), 7425.

[5] Renu G., Divya Rani V.V., Nair S.V., SubramaNIAN K.R.V., Lakshmanan V.K., Adv. Sci. Lett., 6 (2012), 17.

[6] Arumugam A., Karthikeyan C., Hameed A.S.H., Gopinath K., Gowri S., Karthika V., Mat. Sci. Eng. C-Mater., 49 (2015), 408.

[7] Choudhury B., Choudhury A., Mater. Chem. Phys., 131 (2012), 666.

[8] Hu C., Zhang Z., LiU H., Gao P., Wang Z.L., Nanotechnology, 17 (2006), 5983.

[9] Huang Y., Cai Y., QIaO D., LiU H., Particuology, 9 (2011), 170.

[10] Krishnan A., Sreeremya T.S., Murray E., Ghosh S., J. Colloid Interf. Sci., 389 (2013), 16.

[11] Maensiri S., Masingboon C., Laokul P., Jareonboon W., PromaraK V., Anderson P.L., SERAPHIn S., Cryst. Growth Des., 7 (2007), 950.

[12] Maensiri S., Labuayai S., LaOKul P., Klinkaewnarong J., SWATSitang E., Jpn. $J$. Appl. Phys., 53 (2014), 06JG14. 
[13] Phoka S., Laokul P., Swatsitang E., ProMARAK V., SERAPHINC S., MAENSIRI S., Mater. Chem. Phys., 115 (2009), 423.

[14] Sathyamurthy S., Leonard K.J., Dabestani R.T., Paranthaman M.P., Nanotechnology, 16 (2005), 1960.

[15] Suresh R., Ponnuswamy V., Mariappan R., Appl. Surf. Sci., 273 (2013), 457.

[16] TaO Y., Gong F.H., Wang H., Wu H.P., TAO G.L., Mater. Chem. Phys., 112 (2008), 973.

[17] Khana S.A., Ahamad A., Mater. Res. Bull., 48 (2013), 4134.

[18] Thovhogi N., Diallo A., Gurib-Fakim A., MAAZA M., J. Alloy Compd., 647 (2015), 392.

[19] Maqbool Q., Nazar M., Naz S., Hussain T., Jabeen N., KaUsar R., AnwaAR S., Abbas F., JAN T., Intl. J. Nanomedicine, 11 (2016), 5015.

[20] PAsiecznik N.M., Felker P., Harris P.J.C., Harsh L.N., Cruz G., Tewari J.C., Cadoret K., Maldonado L.J., The Prosopis juliflora - Prosopis pallida Complex: A Monograph, HDRA, Coventry, UK, 2001.

[21] Harris P.J.C., PAsiecznik N.M., SMith S.J., Billington J.M., RAMireZ L., Forest Ecol. Manag., 180 (2003), 153.

[22] Seetha Lakshmi B., Naidu K.C., Murthy Y.L.N., Bobbarala V., Pandit N., J. Pharm. Res., 3 (2010), 356.

[23] Hebbar S.S., Harsha V.H., Shripathi V., Hegde G.R., J. Ethnopharmacol., 94 (2004), 261.

[24] Agra M.F., Silva K.N., Basilio I.J.L.D., Freitas P.F., BARbosA-Filho J.M., Rev. Bras. Farmacogn., 18 (2008), 472.

[25] Senthilkumar N., Varma P., GurusubramaNIAN G., Parasitol. Res., 104 (2009) 237.

[26] Ahmad V.U., Sultana A., Qazi S., J. Nat. Prod., 52 (1989), 497.

[27] Ahmad A., Khursheed A.K., SABIHA Q., VIQARUDDIN A., Fitoterapia, 60 (1989), 86.

[28] AHMAD A., KHURSHEED A.K., SABIHA Q., VIQARUDDIN A., Drug Res., 39 (1989), 652.

[29] Satish S., Raveesha K.A., Janardhana G.R., Lett. Appl. Microbiol., 28 (1999), 145.

[30] Kanthasamy A., Subramanian S., GovinDASAMY S., Indian Drugs, 26 (1988), 390.

[31] Gurunathan S., Han J.W., Kwon D.N., Kim J.H., Nanoscale Res. Lett., 9 (2014), 373.
[32] Orel Z.C., Orel B., Phys. Status Solidi. B, 186 (1994), K33.

[33] Tsunekawa S., Wang J.T., Kawazoe Y., J. Appl. Phys., 94 (2003), 3654.

[34] Goharshadi E.K., Samiee S., Nancarrow P., J. Colloid Interf. Sci., 356 (2011), 473.

[35] Kosacki I., Suzuki T., Anderson H.U., ColomBAN P., Solid State Ionics, 149 (2002), 99.

[36] Kos acki I., Petrovsky V., Anderson H.U., J. Am. Ceram. Soc., 85 (2002), 2646.

[37] Barker A., Sievers A., Rev. Mod. Phys., 47 (1975), S1.

[38] Parayanthal P., Pollak F.H., Phys. Rev. Lett., 52 (1984), 1822.

[39] Weber W.H., Bass K.C., McBride J.R., Phys. Rev., B, 48 (1993), 178.

[40] Burroughs P., Hamnett A., Orchard A.F., Thornton G., J. Chem. Soc. Dalton Trans., 17 (1976), 1686.

[41] Abbas F., Iqbal J., Jan T., J. Alloy Compd., 648 (2015), 1060.

[42] Lima R., Seabra A.B., Duran N., J. Appl. Toxicol., 32 (2012), 867.

[43] Hameed A.S.H., Karthikeyan C., Sasikumar S., Kumar S., Kumaresan S., Ravi G., J. Mater. Chem. $B, 1$ (2013), 5950.

[44] Xia T., Kovochich M., Brant J., Hotze M., Sempf J., Oberley T., Sioutas C., Yeh J.I., WiesNER M.R., Nel A.E., Nano Lett., 6 (2006), 1794.

[45] Xia T., Kovochich M., Liong M., Madler L., Gilbert B., Shi H., Yeh J.I., ZinK J.I., Nel A.E., ACS Nano, 2 (2008), 2121.

[46] Burello E., Worth A.P., Nanotoxicology, 5 (2011), 228.

[47] Devasagayam T., Tilak J.C., Boloor K.K., KeTAKi S.S., SARoJ S.G., Lele R.D., J. Assocn. Physicians of India, 52 (2004), 796.

[48] Li Y., Zhang W., NiU J.F., Chen Y.S., ACS Nano, 6 (2012), 5164.

[49] Tong G.X., Du F.F., Liang Y., J. Mater. Chem. B, 1 (2012), 454. 